\title{
STRETCH FORMING USING HEATED DIE
}

\author{
COSMIN CONSTANTIN GRIGORAȘ \\ VALENTIN ZICHIL, EUGEN HERGHELEGIU, CĂTĂLIN TÂMPU, \\ VLAD CIUBOTARIU
}

\author{
“Vasile Alecsandri” University of Bacău, Calea Mărăşeşti 157, Bacau, 600115, Romania
}

\begin{abstract}
The stretch forming process implies stretching and drawing into shape a sheet of material onto a die. This method is used, among other sectors, in the construction of aeroplane fuselage, as significant, complex parts can be obtained in one piece. In essence, stretch forming implies working with materials that have medium to high spring back effects, such as aluminium or magnesium alloys. Different approaches are used in manufacturing due to this phenomenon, ranging from incremental processes to multipoint dies. Another critical aspect of this process is to know how the material behaves under severe plastic deformation, as different alloys require different approaches that vary from step by step forming to inprocess chemical treatments to manual pounding the metal sheet. However, all these alloys have in common that, when heated, their machinability properties improve. In this experimental study, a heated die approach was taken into consideration. 6x60 mm 100W heating elements along with temperature sensors were fitted into the die. The USB/OC326009 metal sheet is in direct contact with the die, thus assuring the heat transfer, as the temperatures reach $200{ }^{\circ} \mathrm{C}$. The die temperature is software controlled so that maximum temperature and thermal inertia could be controlled with ease. The data indicate that this method offers significantly improved results compared to a normal roomtemperature process.
\end{abstract}

Keywords: stretch-forming, temperature, steel sheet, heated die

\section{INTRODUCTION}

The stretch forming process is a metal shaping technique widely used in the aeronautics, shipbuilding, and automotive industries, primarily when manufacturing large curved parts [1]. In recent years industries such as architectural design have adopted this technique for covering curved walls with deformed metal sheets [2]. Advantages such as high efficiency reduced tooling and labour cost, and less waste [3] made this process a viable alternative to other techniques. This process comes in various forms when considering the type of die used: simple or multi-point die stretch-forming. It can be combined with processes such as single point incremental forming when the complexity of the finite part is high [4].

Stretch forming processes imply severe plastic deformation of a sheet of metal that is being drawn into shape using a die. An axial load is applied on the metal sheet so that the material is tensioned as the die pushes progressively. A metal alloy deforms in two stages, plastic and elastic. The point when it passes from plastic to elastic coincides with its Yield strength. As the material is being stretched, it elongates as the force acting upon it increases. Stresses in the material gradually exceed the material's yield strength; thus, plastic deformation is achieved. A significant aspect in stretch forming is its biaxial nature and the UTS (ultimate tensile strength) of the material, as, over this limit, failure occurs. Depending on the mechanical characteristics of each alloy, the elongation from the yield point to the UTS varies. This effect is harder to be controlled in processes such as stretch forming due to biaxial

\footnotetext{
* Corresponding author, email: cosmin.grigoras@ub.ro
}

(C) 2021 Alma Mater Publishing House 
stretching [5]. Another concern is that the stresses induced during this process lead to severe plastic deformation, remaining in the material; thus, elastic spring back is hard to avoid. The stretch-forming process can be applied to any ductile metal alloy, as severe plastic deformation is the main effect that ensures the metal sheet is drawn into shape. Metals such as aluminium alloys are ideal for this process for their mechanical properties and good deformability behavior. At the opposite end, magnesium alloys are known for premature failure and high elastic spring back. Steel alloy sheets are in between as they have a low spring-back effect and good deformability, but high force is needed. To work around this downside a solution is to heat the die and/or the blank as the machinability properties of such alloys improve considerably.

\section{EXPERIMENTAL SETUP}

The stretch forming process was digitally controlled by custom software developed for this application. The schematic representation of the microcontroller and sensors is presented in Figure 1. An Arduino Mega 2560 was programmed to read, interpret the data, and decide. The blue route represents the input data from the sensors, and the red one indicates the controlled elements. The process parameters are inputted in the software, thus when the specified temperature has reached the microcontroller, thru a relay, stops or turn on the power supply to the heating elements; to ensure constant pressure, a motor shield controller, a stepper motor attached to a hydraulic pump valve, by increments of 1.8 degrees, translated into corrections of \pm 0.2 [bar]. Controlling the hydraulic press deformation speed implied simulating a digital potentiometer from within the microcontroller that is connected to the main panel of the press.

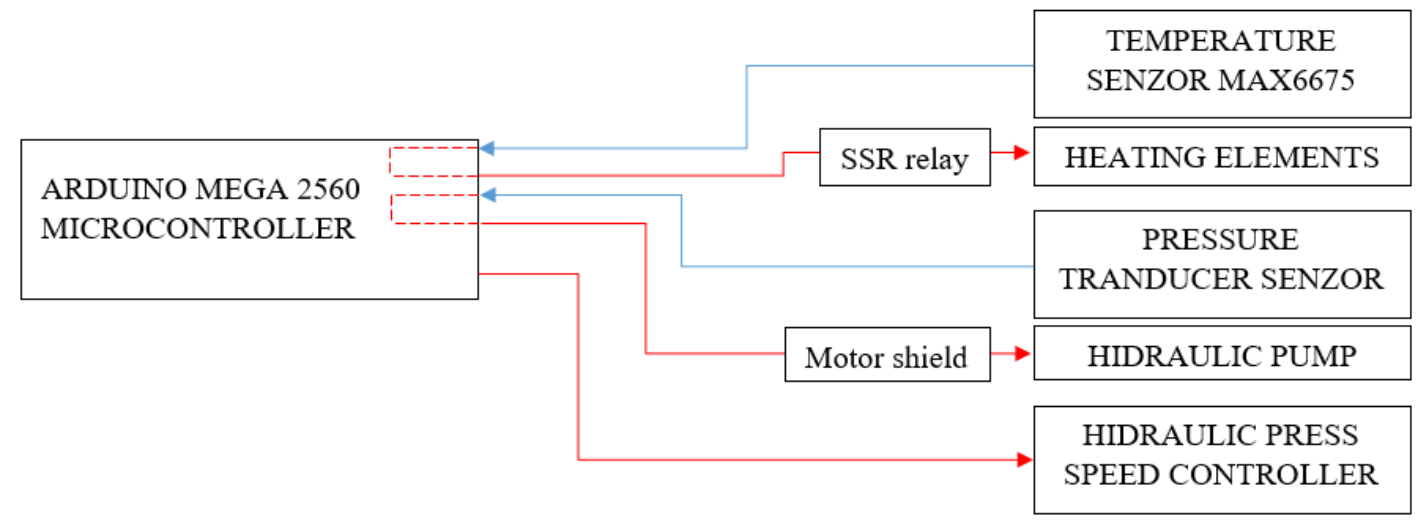

Fig. 1. Digital experimental setup used for controlling the process temperature, pressure and deformation speed.

The experimental setup, presented in Figure 2, consists of a hydraulic press (1) on which a support frame (2) was attached. Two hydraulic pistons (3) were mounted; at the end of each piston, mechanical gripper jaws (4) provide the necessary clamping force. An Ecoroll HGP 3.0 hydraulic pump provides the pressure in the pistons and is digitally read using a pressure transducer sensor.
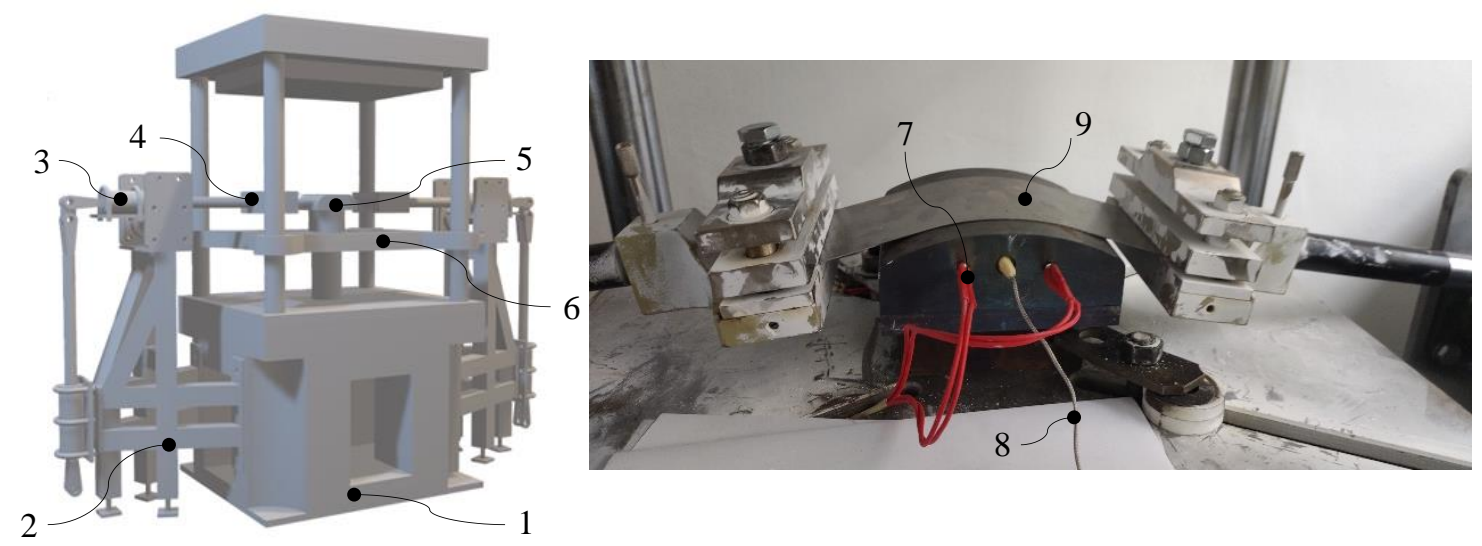

Fig. 2. Stretch forming setup:

1 - hydraulic press; 2 - hydraulic pistons support frame; 3 - hydraulic piston; 4 - gripping jaw; 5 - steel die; 6 - hydraulic driven base plate; $7-6 \times 60 \mathrm{~mm}$ 100W heating elements; 8 - temperature sensor; 9 - steel blank. 
The pressing force is delivered thru a $150 \times 150 \mathrm{~mm}$ with a 150 radius steel die (5) mounted on a hydraulic driven base plate (6); this has a variable speed, software controlled by the Arduino controller, thus controlling the stretch forming deformation speed. The die is heated using four $100 \mathrm{~W}$ heating elements, having a diameter of $6 \mathrm{~mm}$ and length of $60 \mathrm{~mm}$. The heating elements are connected to a relay that is also software controlled using the temperature data read by the temperature sensor (8). A USB/OC326009 steel blank (9), with the chemical composition and mechanical properties given in Tables 1 and 2, was mounted between the gripping jaws, in contact with the metallic heated die.

Table 1. Steel alloy chemical composition.

\begin{tabular}{|c|c|c|c|c|c|c|c|c|c|}
\hline $\mathrm{C}[\%]$ & $\mathrm{Mn}[\%]$ & $\mathrm{Si}[\%]$ & $\mathrm{P}[\%]$ & $\mathrm{S}[\%]$ & $\mathrm{Cr}[\%]$ & $\mathrm{Ni}[\%]$ & $\mathrm{Cu}[\%]$ & $\mathrm{Mo}[\%]$ & $\mathrm{As}[\%]$ \\
\hline 0.03 & 0.23 & 0.02 & 0.009 & 0.006 & 0.02 & 0.01 & 0.02 & 0.001 & 0.001 \\
\hline
\end{tabular}

Table 2. Steel alloy mechanical properties.

\begin{tabular}{|c|c|c|c|c|c|}
\hline $\begin{array}{c}\text { Yield strength } \\
\mathbf{R}_{\mathbf{p} \mathbf{2}, \mathbf{2}}[\mathrm{MPa}]\end{array}$ & $\begin{array}{c}\text { Tensile strength } \\
\mathbf{R m}[\mathrm{MPa}]\end{array}$ & $\begin{array}{c}\text { Elongation for max. } \\
\text { Load } \mathbf{A}_{\mathbf{g t}}[\%]\end{array}$ & $\begin{array}{c}\text { Plastic strain } \\
\text { ratio } \mathbf{~}\end{array}$ & $\begin{array}{c}\text { Poisson's } \\
\text { ratio } \mathbf{~}\end{array}$ & $\begin{array}{c}\text { Young modulus } \\
\mathbf{E}[\mathrm{MPa}]\end{array}$ \\
\hline 218 & 304 & 22.7 & 1.875 & 0.295 & 229542 \\
\hline
\end{tabular}

In this experimental analysis, the authors propose the study of the deformed shape that a sheet of a steel alloy of 320x100 mm, having $1 \mathrm{~mm}$ in thickness, takes after the stretch forming process when using a heated die. A particular aspect emerged during the stretch forming process; the deformation of the material close to the gripping jaws, as highlighted in Figure 3 as "ZONE 1" and "ZONE 2". Thus, in this experimental paper, an analysis of variation (ANOVA) was used to determine how the input factors affect the results from within the Design-Expert software. The analyzed data $(\delta \mathrm{mm})$ represents the difference between the initial width of the blank and the narrower width obtained of the stretch-forming process for each of the two zones. The experimental conditions are presented in Table 3. for room temperature and up to $200{ }^{\circ} \mathrm{C}$. The data analysis is part of a more complex study, from which 12 experimental trials were used for this paper.
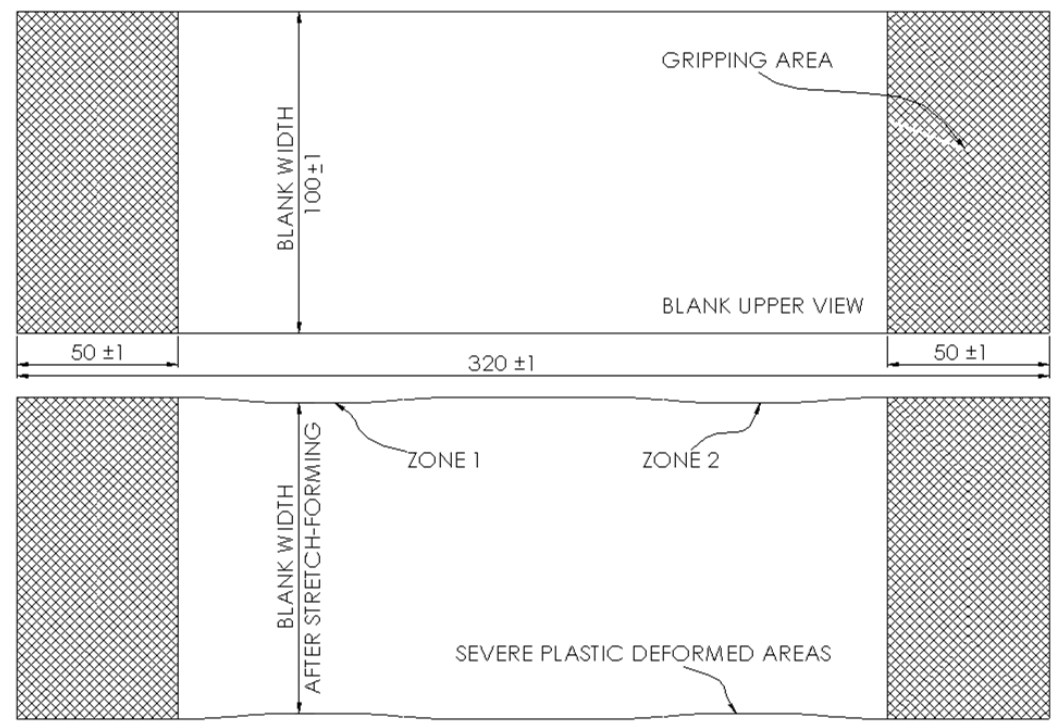

Fig. 3. Stretch forming blank dimensions and main areas of interest.

Table 3. Experimental plan process parameters.

\begin{tabular}{|c|c|c|}
\hline Temperature & Die speed & Stretching pressure \\
\hline $\mathrm{T}\left({ }^{\circ} \mathrm{C}\right)$ & $\mathrm{v}(\mathrm{mm} / \mathrm{sec})$ & $\mathrm{P}(\mathrm{bar})$ \\
\hline $20,100,150,200$ & $0.03,0.33,0.66,1$ & $0,5,7.5,12.5$ \\
\hline
\end{tabular}

\section{RESULTS AND DISCUSSION}

The deformed parts are highlighted in Figure 4, and the process parameters values to which they were subjected. The results were tested for significance using analysis of variance (ANOVA). To each process parameters (input 
factors) or their interaction were assigned evidence against a null hypothesis coefficient as in a p-value; this method allows the interpretation of data with ease as a value higher than 0.05 means that the input is significant and lower than 0.01 is highly significant; values higher than 0.05 are considered not significant. In addition, the R-squared values were used to quantify the mathematical connection between the inputs and the results; a strong relationship is indicated by values above 0.85 . Therefore, this experimental study aims to determine to what extend the process parameters affect the plastic deformation from Zone 1 and Zone 2 (responses).

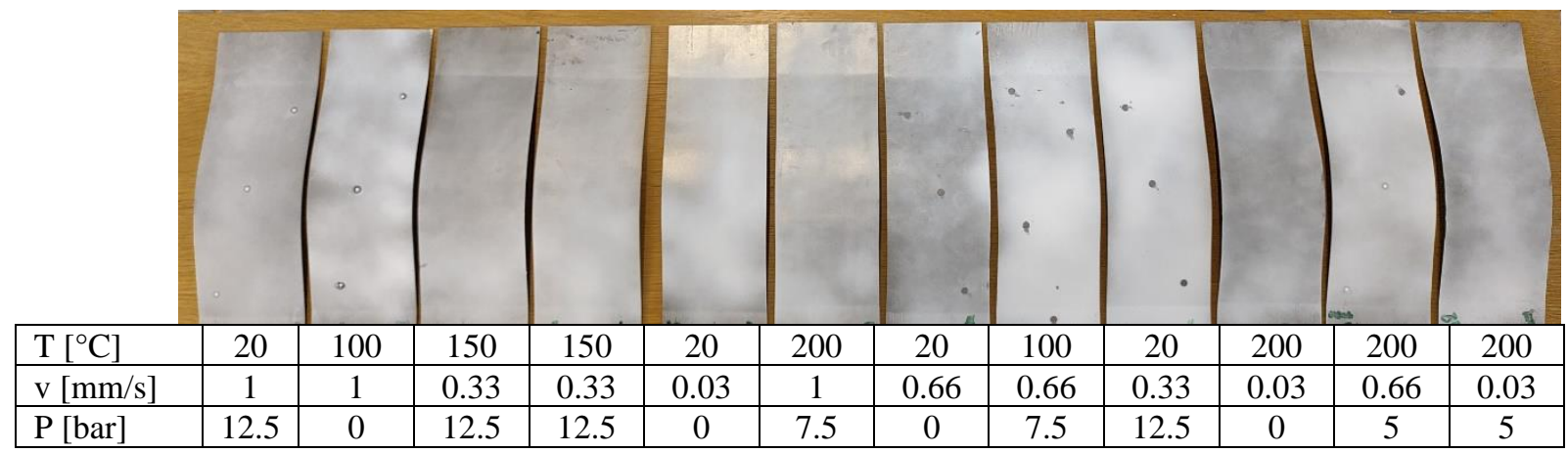

Fig. 4. Stretch forming deformed parts corelated to their process parameters.

The data was analyzed for each of the two zones using a reduced cubic model. In the case of Zone 1, the analysis indicated that the model is highly significant with a p-value smaller than 0.0001 , in agreement with the values obtained to the temperature (0.0037), die speed (0.0011), and stretching pressure $(<0.0001)$. The coefficient of determination R-squared value of 0.982 indicates that data can be used for future predictions of the outcome with high confidence.

The data relating to Zone 2 was analyzed by using a natural logarithmic transformation. Compared to Zone 1, the statistical data differs for each process parameter. The model has a coefficient smaller than 0.0001 , while the temperature, in this case, is 0.9413 , with the die speed calculated at 0.0003 and stretching pressure at 0.0015 . The temperature is considered significant due to its interaction with the other process parameters; a value of 0.0022 was calculated when interacting with the die speed and stretching pressure. Related to this deviation is the value of the R-squared, which is 0.9404.

The ANOVA analysis offers a visual insight into how the input factors influence the response. In this experimental study, 3D model graphs were chosen to highlight the narrowing of each zone concerning the process parameters. The color gradient surface of the graphs is from green to red that indicates small to severe deformation. It can be noted from Figure 5 that the variation $\delta_{z 1}$ has a value between $1.07 \mathrm{~mm}$ and $3.12 \mathrm{~mm}$. The narrowing of the material is highly dependent on the stretching pressure, as expected. Significant deformation occurs when combining the temperature and die speed with the stretching pressure. When stretch-forming with temperatures of $200{ }^{\circ} \mathrm{C}$, severe deformations arise when the pressure increases to 12.5 bar. Deformations of 1.12 to $1.25 \mathrm{~mm}$ occur, regardless of the temperature, from 0 to 2.5 bar. When stretch-forming at room temperature and using high pressure, the deformations remain small, as in $1.65 \mathrm{~mm}$. Minor differences in the width of the blank were noted when varying the die speed. This variation occurs when using pressures above 7.5 bar.

In the other deformed zone, Zone 2 , temperatures above $100{ }^{\circ} \mathrm{C}$ combined with high pressures lead to a variation $\delta z 2$ from 1.32 to $2.87 \mathrm{~mm}$, as highlighted in Figure 6. It can be observed that severe narrowing of the part occurred when stretching at a pressure of $10 \mathrm{bar}$ at $200{ }^{\circ} \mathrm{C}$. A particular aspect emerged when stretch-forming with 12.5 bar at room temperature, as the variation $\delta_{\mathrm{z} 2}$ is below $1 \mathrm{~mm}$. In the case of the die speed, the deformations are of the order of tenths of a millimeter with the highest values recorded when using $0.03 \mathrm{~mm} / \mathrm{s}$. Thus, maximum deformations were obtained stretch pressures above 10 bar were used. A particularity appears when using maximum values for pressure and speed.

The shape of the graphs indicates that this is a complex process when trying to predict the results considering the process parameters. Therefore, a mathematical relationship is necessary, as the process is not a linear one. The mathematical equations for Zone 1 and 2 are highlighter in equations (1), respectively (2). The coefficients that are assigned to each factor and interaction are correlated to the significance that they have. For each case, the die temperature has a minor influence on the outcome compared to the pressure and die speed and their interaction. 


$$
\begin{aligned}
\delta_{\mathrm{z} 1}= & -1.33+0.013 \cdot \mathrm{T}+0.124 \cdot \mathrm{v}-0.285 \cdot \mathrm{P}-0.007 \cdot \mathrm{v} \cdot \mathrm{T} \cdot \mathrm{P}+0.7 \cdot \mathrm{v} \cdot \mathrm{P}-0.000003 \cdot \mathrm{T}^{2}+0.03 \cdot \mathrm{P}^{2}- \\
& 0.05 \cdot \mathrm{v} \cdot \mathrm{P}^{2}
\end{aligned}
$$

$$
\begin{gathered}
\delta_{\mathrm{z} 2}=\ln \left(-2.93+0.007 \cdot \mathrm{T}-0.78 \cdot \mathrm{v}-0.133 \cdot \mathrm{P}-0.001 \cdot \mathrm{T} \cdot \mathrm{P}+0.75 \cdot \mathrm{v} \cdot \mathrm{P}+0.02 \cdot \mathrm{P}^{2}+0.00007 \cdot\right. \\
\left.\mathrm{T} \cdot \mathrm{P}^{2}-0.06 \cdot \mathrm{v} \cdot \mathrm{P}^{2}\right)
\end{gathered}
$$
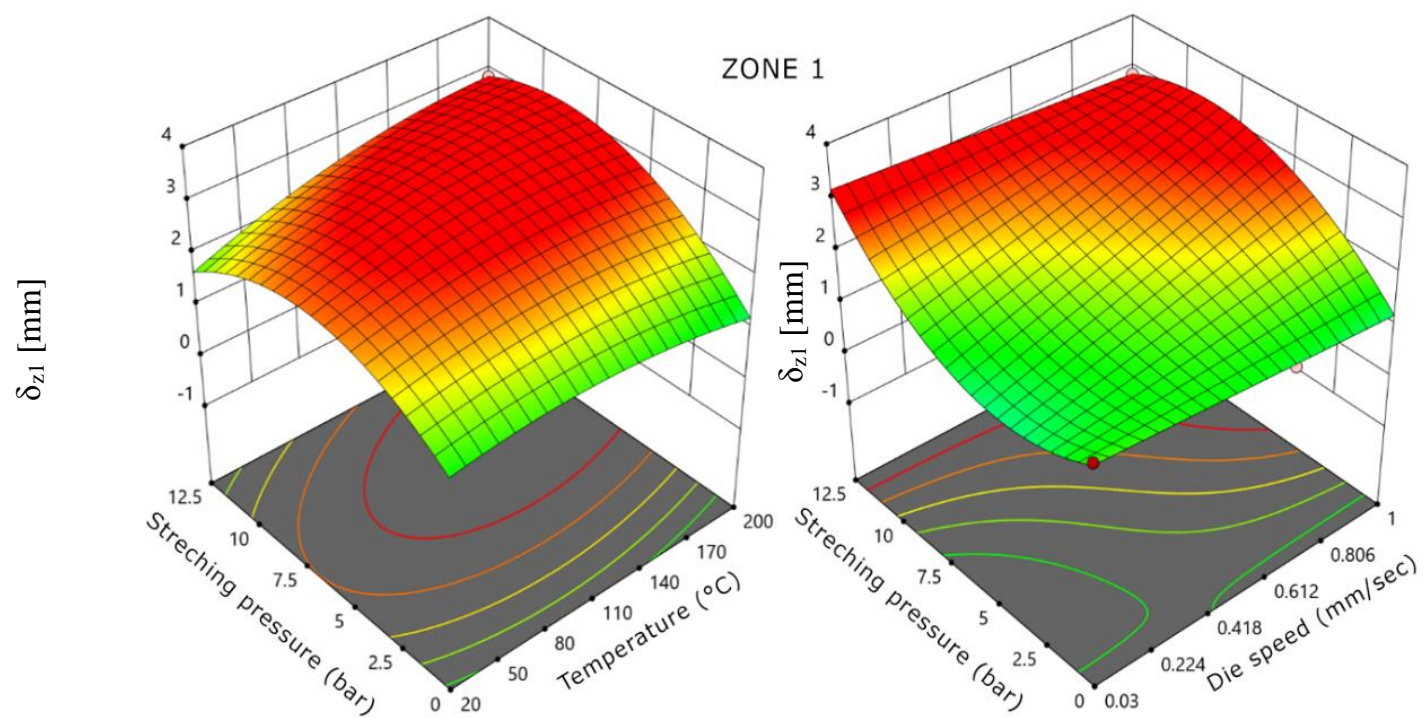

Fig. 5. Stretch forming 3D model graph of the ANOVA analysis for the deformation in Zone 1, depending on the stretching pressure, pressure and die speed.
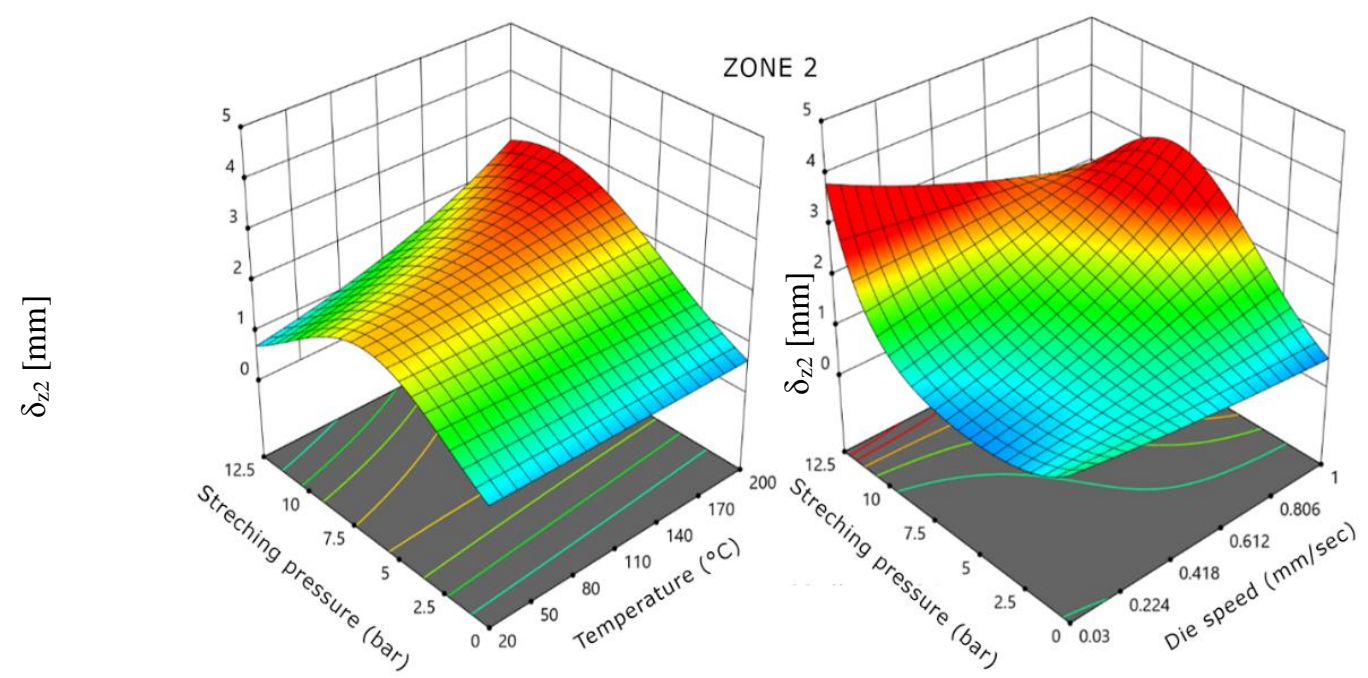

Fig. 6. Stretch forming 3D model graph of the ANOVA analysis for the deformation in Zone 2, depending on the stretching pressure, pressure and die speed.

\section{CONCLUSIONS}

The analysis of the experimental data concludes that a significant relationship emerged between the narrowing of the material in the vicinity of the gripping jaws, concerning the process parameters, when stretch-forming is applied using a heated die and steel alloy USB/OC326009 blanks. During the measurement, no significant thickening of the material was noted.

The experimental study indicated that the two zones behave differently; this phenomenon is assigned because the material flows uneven, allowing one zone to be narrowed more than another once the Yield stress is achieved. The ANOVA analysis indicates that this deformation is assigned mainly to the stretching pressure, as axial forces 
assure that the material is stretch, and considering the conservation of volume, these zones form as a response to the stress developed. The data of the model graphs indicate that the severity of the deformation is shifted to the weaker zone, an aspect that can best be observed when high pressure and high temperatures are used. Although the temperature is less significant, compared to the pressure and speed, the most severe deformed part was obtained at $200{ }^{\circ} \mathrm{C}, 5 \mathrm{bar}$, and $0.03 \mathrm{~mm} / \mathrm{s}$; it can be inferred that material had an increased elongation as the stretch-forming process lasted for 0.37 hours thus allowing the material to deform slowly.

We consider that high axial forces combined with slow deformation speeds offer results that assure the pars are drawn into shape. The data indicate that temperatures above $200{ }^{\circ} \mathrm{C}$ lead to the malleability of the material.

\section{ACKNOWLEDGEMNT}

This work was supported by a grant of the Romanian Ministry of Research and Innovation, CCCDI - UEFISCDI, project number PNIII-P1-1.2-PCCDI-2017-0446 / 82PCCDI / 2018, within PNCDI III.

\section{REFERENCES}

[1] The stretch forming process, https://www.techniform.com/stretch-forming/3605279 (25.04.2021).

[2] Lee, G., Kim, S., Case study of mass customization of double-curved metal façade panels using a new hybrid sheet metal processing technique, Journal of Construction Engineering and Management, vol. 138, no. 11, 2012, p. 1322-1330.

[3] The history of stretch bending in manufacturing, 2018, https://ltcroll.com/history-stretch-bendingmanufacturing/ (25.04.2021).

[4] Brabie, G., Rizea, A.D., Cărăușu, C., Chicea, A.L., Maier, C., Review of recent stretch forming development, Proceedings in Manufacturing Systems, vol. 13, no. 3, 2018, p. 147-152.

[5] Dal Santo, P., Germain, G., Boude, S., Giraud, E., Cold forming by stretching of aeronautic sheet metal parts, International Journal of Computer Integrated Manufacturing, vol. 27, no. 2, 2014, p. 129-138. 